\title{
Erratum to: Amylin(1-8) is Devoid of Anabolic Activity in Bone
}

\author{
Maria Ellegaard · Christian Thorkildsen · Solveig Petersen • \\ Jørgen Søberg Petersen - Niklas Rye Jørgensen - Rasmus Just • \\ Peter Schwarz $\cdot$ Martha Teresa Ramirez $\cdot$ Martin Stahlhut
}

Published online: 3 March 2010

(C) Springer Science+Business Media, LLC 2010

\section{Erratum to: Calcif Tissue Int}

\section{DOI 10.1007/s00223-010-9338-3}

Unfortunately, a mistake was unintentionally introduced in the name of one of the authors. In the list of authors, Maria Teresa Ramirez should be replaced by Martha Teresa Ramirez.

The online version of the original article can be found under doi:10.1007/s00223-010-9338-3.

M. Ellegaard · C. Thorkildsen - J. S. Petersen - R. Just ·

M. T. Ramirez - M. Stahlhut

Zealand Pharma A/S, 2600 Glostrup, Denmark

M. Ellegaard · S. Petersen · N. R. Jørgensen · P. Schwarz Department of Geriatrics and Rheumatology, Research Center for Aging and Osteoporosis, Glostrup Hospital, 2600 Glostrup, Denmark

M. Stahlhut ( $\square)$

LEO Pharma A/S, Industriparken 55, 2750 Ballerup, Denmark

e-mail: martin.stahlhut@leo-pharma.com 